\title{
Regional Industry Analysis: An Approach for Economies Large and Smaller
}

\begin{abstract}
Some challenges communities of all sizes face in identifying the strengths and weaknesses in their regional economy include access to the data and the complexity of the models available to evaluate their regional economies. This research proposes a holistic and accessible method of industry analysis and applies it to the [name removed for review] metropolitan statistical area. By combining a quantitative quadrant method with a qualitative analyses based on focus groups and interviews, our synergistic approach not only more accurately identifies industry clusters than any isolated approaches, but also more concretely examines the multi-dimensional links between industries and their ties. This methodology is applicable to virtually any size community to learn about its economic strengths and weaknesses and make decisions on where to target its resources for the benefit of a community.
\end{abstract}

Keywords: industry analysis, regional economy, economic development

\section{Introduction}

Interest in cluster analysis for economic development in regions has been significant over the years. Knowing the strengths and weaknesses of a community's industry clusters or economic agglomerations can provide regions with resilience to economic changes. Large and smaller economies that are able to identify their industry clusters and know their competitive strengths and weaknesses may be more adaptable and thwart the negative effects of economic change. One example of the value of knowing about the strength and weakness of an economy and the potential to shift to new areas of production and service in a local economy is evidenced in Walla Walla, Washington. Small communities such as Walla Walla have a competitive advantage in wheat production but have found the need to transform their economies as a result of global competition making their wheat crop production less competitive. Walla Walla packaged some of their natural amenities and their strengths in crop production, made use 
of the education infrastructure at their community college, and created a new industry stronghold of wine production and tourism with restaurant and hotel attractions (Public Broadcast Systems 2013). Capitalizing on their competitive advantage in crop production plus moving from wheat to grapes were both necessary to stay competitive, but unlikely to be successful had they not built on their existing competitive stronghold in agriculture and made use of their community college to share and disseminate knowledge in wine production.

The research highlighted in this paper provides a cost-effective approach that most communities can use to understand their local economies. A lack of resources in terms of labor skills or knowledge, or insufficient funding to acquire someone with such skills or knowledge, or limitations on data availability can impede communities from having the information they need to further assist their local economies. Our paper provides an analytical approach, or more accurately a battery of tools, that reduces the complexity and thereby resources required to perform a cluster analysis. Our approach is robust and accessible to communities lacking resources such as knowledge, funding, or data. To that end, each of the tools presented is selected based on accessibility to practitioners. Our approach included a quadrant analysis at the industry sector and sub-sector levels to identify industries that have demonstrated competitiveness in the region through resilience to employment loss, if not growth, as well as a series of focus groups and interviews to discern which industries are heavily embedded within the region. The quadrant analysis leads directly to a better understanding of the employment needs of our study area. Thereafter, interviews and focus groups with local business owners, economic developers and chambers of commerce representatives are detailed to provide further insight into the local economy and its industry sectors. The ultimate intent of the research is to describe and understand the current and potential future employment training needs to help keep a particular economic region competitive and potentially resilient to the negative impacts of economic change. Finally, as a demonstration we developed a cluster map for those that would want to take their analysis to that level. Our synergic 
approach provides a means for a robust analysis and can be adjusted for very small communities that do not have access to some types of census data ${ }^{1}$. Additionally, the costs that this approach imposes on local communities are marginal, as articulated later in this paper.

This paper is organized as follows. We first identify and discuss why we pursue the use of a battery of tools as opposed to one specific approach for cluster analysis for understanding the strengths and weaknesses of a local economy. The next section puts forth a synergic approach using a combination of methods to generate a holistic assessment of a community's economic regional strengths and weaknesses. The hybrid methodology that is advanced in this manuscript marries quantitative data with qualitative data from interviews and focus groups. Our mixed-methods approach further grounds our understanding of the multi-dimensionality of community employment and industry agglomerations. The next section applies these methods to the Boise-Nampa MSA to demonstrate how our synergic approach can be used in practice and benefit a community. We then discuss the concerns and benefits of our synergic approach, followed by the conclusion session.

\section{Our Synergic Approach}

\section{Description}

The approach we used to create the battery of tools needed, required determining a combination of methods that would result in the most holistic and robust findings as well as be accessible to the greatest number of practitioners and communities. We considered data accessibility, relative low need for funding, and the need to avoid tools that required hyper-specific knowledge, software or technical expertise. We wanted to use both quantitative and qualitative data when possible to get the most complete picture of our clusters. Ultimately, we borrowed principally from Blakely and Green-Leigh (2010) and Austrian (2000) and used the validated ideas of other scholars to create a holistic, robust, and accessible method of industry cluster analysis. 
Our approach began with the Blakely and Green-Leigh quadrant method that uses accessible data in most communities (with the exception of those very small communities due to data confidentiality requirements) to calculate location quotients and to provide national comparisons with the shift-share analysis. Blakely and Green-Leigh (2010) identified clusters quantitatively to assign industries within a region into a four-quadrant table. Their model drew on economic base theory to classify and create a cluster analysis of transforming, declining, growing, and emerging clusters. They created a four-quadrant table of non-competitive and competitive clusters determined by low and high shift share quotients, crossed by low and high local industry concentrations as determined by the location quotients at both the two and three digit industries as seen in Figure 1. The upper half of the quadrant includes industries in the area that maintain location quotients greater than 1.0. The right half of the quadrant contains those industries that maintain a positive location differential calculated from shift-share analysis. These two calculations allow for the categorization of industries into one of the four quadrants. The upper-right quadrant contains the growing base industries, the upper-left quadrant contains the transforming industries, the lower-right quadrant contains the emerging industries, and the lower-left quadrant contains the declining industries. Industries can then be grouped together based on known and obvious linkages or through other quantitative screening to develop a series of clusters. After removing inappropriate industries (e.g., non-exporter, single dominate firms), the authors then looked for related industries. Thereafter they began to identify supplier linkages and marketing channels. They noted using input-output tables could be helpful in identifying the suppler linkages. Finally, the authors suggested considering the local infrastructure and the way it may or may not help shape the cluster.

[Insert Figure 1 about here- Quadrant Method]

Applying the Blakely and Green-Leigh quadrant method, this first step of our approach not only provided information about industry strengths and weaknesses but also began to point to potential 
employment needs. One strength of the quadrant method is the data required is typically readily available from the U.S. Census and Bureau of Labor Statistics. One drawback is the restrictions applied to the release of data when specific employers may be identified, such as sectors that have low employment or where one employer dominates a particular sector. The limitations of data availability may be more acute for smaller communities. Reid et al., (2008) note that another drawback to location quotients is they are specified within a particular areal unit such as county or metropolitan statistical area without regard for a neighboring unit's industrial structure. At the same time, information on geographic models suggests this drawback may not be significant enough to affect its use.

The next step of our approach involved a qualitative analysis, which utilized the quadrant analysis to identify businesses within specific industries to contact for focus groups and interviews. Our selection criteria for participation in focus groups and interviews involved specific businesses within the industry sub-sectors that had a location quotient above 1.25 and a regional competitive advantage of at least 420 employees as compared to the national and/or industry expectations in employment changes between 2006 and 2010. Due to space constraints the results and detailed tables from our quadrant analysis can be accessed at http://career.boisestate.edu/collegiate-employmentworkforce-readiness/. In addition, interview and focus group participation was sought across the region looking for diversity in size and geographic location as well as business diversity within the industry sub-sector.

Our synergic approach that combines quantitative and qualitative research to identify and further understand the nature of clusters is inspired by Austrian (2000). Austrian used qualitative tools to complement the analytical analysis promoted by Hill and Brennan (2000). Austrian provided a strong framework for conducting the qualitative component of an area cluster analysis through personal interviews, the accompanying interview analysis, and the construction of a cluster map, which is a visual representation of the interactions between industries in the identified cluster. Knowledge obtained from personal interviews and subsequent analysis will produce additional information necessary to 
better understand the intricacies of the industry cluster, potentially identify clusters that were not evident through the quantitative component of the analysis, and/or identify non-quantitative strengths or weaknesses in each cluster, such as the existence of industry collaboration or broader social interaction, or the lack thereof. Unlike a purely statistical approach, Austrian contends "the cluster engagement phase should be based on what the companies themselves perceive as their main issues, barriers, and (ultimately) cluster composition" (p. 98)². Combining both quantitative and qualitative methods reveals the factors that shape the evolution and competitiveness of the industry structures (Austrian, 2000).

Additionally, her research investigated both existing and emerging clusters as identified by location quotients, employment growth rates, relative product, and out of the region export activities. The case studies ultimately made use of descriptive data, literature on the historical development of the clusters and interviews with cluster leaders. The interviews afforded key knowledge on the interconnections with firms, institutions, and other supporting infrastructure (Austrian 2000). This element is especially important. If a cluster is currently competitive, it is unlikely that it will maintain its competitiveness for very long if innovation is sluggish due to a lack of social interaction or collaboration. Therefore, it is not solely the business-level interaction, such as buyer-supplier relationships, but also the relational and communicative interaction which fosters ties between businesses, educational institutions, local and state government, and other agencies which potentially leads to innovative processes and/or products. Ultimately, Austrian (2000) used the cluster maps to describe the way various components of a cluster are related to one another. Although cluster maps are dynamic in terms of future connections and changes, they become the way clusters are perceived by individuals both inside and outside of the cluster. The benefit to the qualitative approach is that it allows more specific details to be gathered and provides a means to create cluster maps that can inform policymakers' decisions. Again, conducting interviews can be labor intensive, but the unique information gained for 
each cluster may be invaluable for developing a tool that helps a local economy better understand the strengths and weaknesses within their economy.

Following the quadrant analysis, the focus groups and interviews allowed us to begin to identify supplier linkages and marketing channels and consider the local infrastructure and the way it may (or may not) help shape the regional economic strengths and weaknesses. Social network analysis could have been employed at this juncture; but by drawing on the questions from Austrian's protocol, the questions we used were not necessarily designed for use in social network analysis. Additionally, social network analysis is complex and outside the reach of many communities in terms of the necessary knowledge and skills. As such we did not include it as part of our battery of tools, but note its potential here as an option for communities that may choose to use it. The interviews also permitted the exploration of shared labor and other ways the industries collaborate. Prior to the interviews, relevant industry histories were developed to further our understanding and assist with the industry cluster maps. The quadrant analysis results were verified for accuracy with the interviewees and focus groups. The focus group questions were developed specifically for this methodology as seen in Table 1 . The interview questions were drawn from Austrian's interview protocol (2000, p. 100) with additional questions added for key interviews with people specifically knowledgeable about the interrelatedness of factors within the industry as seen in Tables 2 and 3. The industry histories were verified for accuracy in the interviews. Emulating the cluster map method used by Austrian, we developed two cluster maps, from the for the crop production industry food manufacturing industry sub-sector in the growing category of the quadrant. We drew from information in the focus groups, interviews and key interviews with specific people who had knowledge about the interrelationships among the firms within the industries. Ultimately the questions specifically used to create the cluster maps were drawn from Austrian's interview protocol as well as questions we developed as seen in Table 2. 
Overall, our approach used publicly accessible data (e.g. Quarterly Census of Employment and Wages (QCEW) dataset) and we complemented it with qualitative analysis (e.g. focus groups and interviews) to provide a rich understanding of the challenges and advantages, inter-relatedness of suppliers, infrastructure and labor needs that would not otherwise have been acquired. Using only the quadrants would not have allowed the rich capture of the needs and inter-relatedness of the economic complex. Using only interviews with no data or a foundation about the regional economy would have left researchers with little information to determine systematically which industries and businesses to seek out for interviews or the knowledge of area industry composition. It is for these reasons we drew specifically from tools that use publicly accessible data and were not overly cumbersome in terms of time and energy for the interviews needed to provide sufficient data to conduct our analysis.

Note that the Boise-Nampa MSA maintains relatively available employment data at the industry sub-sector level, which is a necessity for conducting the first step quadrant analysis. For communities with smaller populations or those encountering other data limitations, we could perform the analysis at an aggregated geographic area and focus the qualitative component on identifying how their community fits within the economic agglomerations of the region. Another option in the places where detailed employment data is not available is to cull local knowledge. In essences, it may be more obvious to local planners and professionals what the industry strengths are in these small communities and thus, it may not be as necessary to formally create the industry quadrants. In smaller communities, local planners or economic development professionals could sketch their own quadrants from what is widely known in the community about the industries, even if they cannot be explicitly drawn from data.

[Insert Tables 1, 2, and 3 about here]

\section{The Application of our Synergic Approach to the Boise-Nampa MSA}

In the application of the methodology, both 2-digit and 3-digit industry employment data, as classified by the North American Industry Classification System (NAICS), were obtained from both the 
Bureau of Labor Statistics website and personal correspondence with the Idaho Department of Labor. Average annual employment by industry from the QCEW dataset for the nation and Boise-Nampa MSA between 2006 and 2010 was used to calculate the local shift component of the quadrant, while the 2010 QCEW data alone was used to calculate the location quotients. Since our research initiated in September of 2011, the 2010 data was the most recent data available at the time. The computed local shifts and location quotients are used to classify our four quadrants: Transforming, Growing, Emerging and Declining industries. For location quotients, the thresholds of .75 and 1.25 were used since they are the accepted rule of thumb in terms of cut-offs for the methodology.

Using the information from both 2-digit and 3-digit quadrants, focus groups were scheduled with local economic developers, chambers of commerce, and business owners or representatives of specific businesses that are classified as exporting industries in the Transforming and Growing quadrants. Exporting industries are identified as those industries maintaining a location quotient greater than 1.25. Industry-specific businesses were identified using the online business directory provided through the Idaho Department of Labor, which included those businesses having voluntarily selected to provide information, such as NAICS, residing county, and employment range ${ }^{3}$. One industry, Heavy and Civil Engineering Construction, did not produce any business contacts. In light of this, the business directory within the Idaho Chapter of the Associated General Contractors of America website was utilized to identify businesses operating in the Boise-Nampa MSA. A total of five structured focus groups were conducted. We deliberately aimed to have small groups of four to six people per group to ensure an opportunity for all attendees' participation and still provide time to explore responses in more depth during the two hour sessions. After contacting 11 to 16 businesses and agencies as deemed necessary for each type of focus group, we had commitments from five to six people for each group. The lead researcher who is an experienced facilitator of focus groups conducted all five sessions. Two other researchers took notes to help identify themes and make sure all the data were captured not just on the 
flipcharts, but also in note form as well as electronically recorded for analysis thereafter. Two focus groups were comprised of both chambers of commerce representatives and local economic developers at the city and regional level. Participant levels numbered five and three in these two sessions. The remaining three focus groups were industry-specific, including only business owners or representatives of firms within a particular industry at the 2- or 3-digit NAICS level. As there were a few "no shows" in each session, there were three participants for two of the industry-specific focus groups--Agriculture industries and Administrative and Support Services industries, and only one participant in the third session on Computer and Electronic Product Manufacturing industries. While each of the business owners or representatives contacted to participate in a focus group were from the same industry at the 2-digit NAICS level, the businesses were diversified by employment sizes, geographic locations (counties within the MSA), and industry specializations at the 4-, 5-, or 6-digit NAICS level. Focus group participants were asked a series of questions on area competitiveness, opportunities for industry diversification, business expansion, and knowledge transfer (see Table 1). The information gained through the focus groups provided insight into economic strengths and weaknesses of selected industry sectors in the region. Following the completion of focus groups, we reviewed the two note-takers' notes, audio recordings, and information written on the flipchart paper. The information was then summarized to identify recurring themes among all participating groups.

Interview participation was sought across quadrants to provide further understanding of the economic strength and weakness of the region. The selection criteria involved diversity in size and geographic location, as well as business diversity within the industry subsector. The method for identifying key industries in each quadrant differs somewhat. For Transforming and Growing industries, the businesses selected for interview maintained LQs greater than 1.25 (i.e. exporting industries). The Emerging industry interviews included those industries that maintained the highest local shift change between 2006 and 2010 and a LQ between 0.75 and 1 . To determine a sufficiently high local shift, 
industries in the emerging quadrant are sorted from highest to lowest local shift, where a noticeable break in the local shift figure between industries is chosen. In this research, nine industries were obtained and the cutoff occurred when the local shift negatively changed from one industry to the next by nearly 50 percent. For the category of Declining industries, the 2-digit industry code was first used to identify the industry that experienced the largest employment loss--in this case, 31-33 Manufacturing. Within the parent 31-33 Manufacturing 2-digit industry, the 3-digit industries with the largest decline in terms of the local employment shift share were then selected according to the 3-digit industry quadrant. Again, the business directory through the Idaho Department of Labor was utilized to identify businesses within each selected 3-digit industry. Prior to conducting interviews with the identified industries, a brief industry history was read to interviewees by the researchers to further vet the accuracy of our datadriven quadrant analyses in terms of understanding of their specific industry. With the above selection criteria and within the nine primary industry areas, we identified fourteen sub-sector industries for interviews (see Table 4). It was not possible to conduct interviews with representatives from all industries listed in each segment of the quadrant at the 3-digit NAICS level, however key businesses were sampled from each industry. We attempted to obtain diversity in size and geographic location of the businesses for interviews. After we identify establishments we first called them and then followed up with email to either ask for their participation (with confirmed date, time and location) or sent them the interview questions in advance of the interviews and requested a confirmed date, time and location. Only about half the industries contacted permitted an interview. The three researchers went to the establishments of the interviewees to conduct the interviews. Each interviewee was asked to complete a consent form and whether they were willing to have the interview electronically recorded. All interviewees agreed to electronically recording, but hand written notes were also taken during the course of the interviews. All interviewees were assured the interview would last one hour or less. Interviews only exceeded that time limit if the interviewee wanted to continue the session or give a tour 
or demonstration of the work or production that went on at their establishment. In the end we achieved a cross-sample of industries within each group and made every attempt to get more than one business from each industry. Ultimately the data obtained is sufficient to glean insight into some of the strengths and weaknesses the regional economy. Additionally, the snowball method was then employed to identify potential future interviewees that may be helpful in further understanding each of the respective industry ties.

[Insert Table 4 about Here]

To take the methodology application to its completion, one industry sub-sector was selected for the creation of two cluster maps within the sub-sector of Food Processing. Interviews were conducted with key people, identified through previous interviews as knowledgeable about the factors related to interconnectedness within the industry.

Interview questions were catered to the development of cluster maps as adapted from Austrian's methodology. In addition, questions surrounding requirements for industry growth and the impacts of technological and global changes were also asked to identify threats to the competitiveness of the clusters in the region. The cluster maps generated through the interviews illustrate the respective cluster through six categories of information: 1) Final Markets; 2) Distribution Channels; 3) Export Services; 4) Suppliers; 5) Specialized Community Infrastructure; and 6) Threats. The final markets category lists the various markets for which the respective clusters' products are consumed, whether this is for further processing or consumption. The distribution channels category provides the means for which the product is transported to and from businesses within the cluster. The export products category contains the products produced by the cluster and exported out of the region. The supplier category contains the industries that supply the raw and other materials necessary for product creation. The specialized community infrastructure category provides the infrastructure which is integral for 
cluster operations. Finally, the threat category provides any dependencies that threaten the economic viability of cluster expansion or general operations in the region.

The cluster maps in Figures 2 and 3 for Frozen Potato Processing and Dairy Processing describe linkages between industries that form two examples of food processing clusters in the Boise-Nampa MSA. The cluster maps describe not only the final markets for the products, but also the distribution channels for each food processing structure, and the final products. Suppliers and specialized community infrastructures are also identified. Finally, the interviews revealed potential threats to the success of these food processing industries.

[Insert Figures 2 and 3 here]

\section{Potential Concerns and Benefits of the Synergic Approach}

An obvious critique of our hybrid approach is that it could be more mathematically driven. In recent years, one approach that gained significant attention was the mathematically driven cluster analysis put forth by Hill and Brennan (2000). Hill and Brennan created a sophisticated data driven model employing both traditional methods from economic base theory such as location quotients and shift share analysis, as well as statistical techniques of cluster analysis and stepwise discriminate analysis to identify drivers of the economy. The methods are sound but difficult to employ without access to the necessary data. In their analysis, Hill and Brennan also made additional investigations using inputoutput models to identify linkages within regional industries. They used statistics as the driving force in identifying the clusters. This methodology is one of the most comprehensive quantitative models for performing cluster analysis, but even the authors noted that they were fortunate to obtain access to the detailed establishment-specific data utilized in their analyses (Hill \& Brennan 2000, p. 71). As such, the complexity and data requirement of Hill and Brennan's model renders it less useable for many communities than other approaches. 
Held (2004) replicated much of the Hill and Brennan methodology in a comparison across seven metro regions. Even after he purchased data through IMPLAN for regional coefficients he felt the information was not precise enough to make the buyer-supplier linkages and chose to let policy-makers explore those linkages (p. 387). In Hill and Brennan's study they struggled with making specific thresholds in their discriminant analysis and this resulted in Held needing to create his own decision rules to ensure consistency across the seven metropolitan regions. Illustrating that even highly mathematically driven objective analysis may take on some subjective or non-data driven decision making to apply it in practice. This being the case, perhaps a simpler more transparent model would be just as effective and at the same time more accessible to communities competing in a global era.

Peters (2005) also made use of Hill and Brennan's methods and occupational data but instead of industries he used the method to develop industry labor complexes to explain why certain industries are drivers. Using multivariate analysis of variance (MANOVA) and discriminate function analysis he grouped labor complexes that would not be hidden in smaller economies. This process culminated in an outcome similar to cluster analysis that tends to be drawn to the core of regions as opposed to the periphery. The focus on labor is more amendable to policy changes, where actions can be directed for public-private partnerships in training to assure a skilled labor force, or marketing for industry that can use the skills of particular labor complex. Peters' approach recognizes the knowledge spillovers among industries with a shared labor force that occurs both formally and informally among skilled workers or mobile labor ( $p$. 141). Although the data Peters uses is more readily available than that of Hill and Brennan, the ability to determine the valuable labor complexes requires a rather sophisticated mathematical analysis. In short, some models have become so complex that the technical expertise needed to conduct the analysis may be beyond a community's reach.

Additionally, there is also no agreed upon methodology for identifying clusters (Reid, et al. 2008; Blakely \& Green 2010; Koo 2005; Martin \& Sunley 2003; Boschman \& Kloosterman 2005). Most models 
have a theoretical underpinning that drives the focus of the 'glue' for what makes a cluster. That glue can range from factors such as geography, knowledge transfer, labor supply, or buyer supplier linkages (Koo 2005, p. 1487). Industry clusters share scale, scope, and activity complexity (Parr, 2002). As such, industry clusters are very complex agglomerations that share horizontal, lateral, and vertical integration (Parr 2002, p. 154; Martin \& Sunley 2003, p. 10). Most models that attempt to identify industry clusters focus on one or two of these 'glue' aspects at a time. As a result, most models, no matter their sophistication, are not grasping for the complete picture or dynamics of the industry cluster.

Our synergic approach that integrates quantitative analyses with focus groups and interviews is relatively simple to conduct and thus has a big advantage for smaller to medium-sized communities that are facing a lack of resources (e.g. lacking necessary knowledge, skills, data availability to perform their own analysis, or the financial means to obtain an analysis from a third-party). Moreover, our synergic approach is able to not only more accurately identify industry clusters than any isolated approach, but also more concretely examines the multi-dimensional links and ties between industries.

The first part of our synergic approach-the quadrant method-takes advantage of the publicly available data from the U.S. Census and Bureau of Labor Statistics. Through location quotient and shift share analyses, the quadrant method is a less sophisticated mathematical analysis that does not require a high level of technical expertise to conduct and thus all communities may be able to take advantage of it for their economic development policy. The quadrant method is able to identify existing clusters that may require a closer examination of potentially emerging clusters for our regional economy. Therefore, it has the advantage of providing a base (i.e. national employment) for comparison and a starting point for understanding the comparative advantages of a regional economy. However, while the quadrant method may identify industry clusters, using this method alone does not explain the linkage between clusters and thus it is insufficient to reveal the unique qualities of the regional industry network. For 
example, it ignores gaps in the supplier chains that also might relay valuable information about local comparative advantages where key sectors may be interacting and sharing labor with local cluster firms.

The second part of our synergic approach-qualitative analyses based on focus groups and interviews - substantially complements the quadrant method and provides in-depth knowledge that is hard to discover in any other way. First, although the quadrant method is able to identify emerging industries, the qualitative analyses may be helpful to identifying industry clusters that are in the process of forming but do not show up based on currently available data. The focus groups and interviews also help vet findings from our quantitative industry cluster analysis. Second, our qualitative analyses augment what we know about the way clusters work (i.e. the factors that shape the evolution and competitiveness of the industry clusters) as well as the issues faced by different industry clusters. Through the focus groups and interviews, we are able to identify supplier linkages, marketing channels, shared labor force, and local infrastructure needs that would not have been attained from the quadrant method alone yet are clearly critical to the prosperity of our industry clusters. Third, the focus groups and interviews provide us with a more comprehensive understanding from the participants' perspective, of the challenges and advantages, inter-relatedness of suppliers, infrastructure and labor needs. Focus groups and interviews also provide a great opportunity for companies to speak out to researchers and policy makers on what they perceive as their cluster composition as well as the main issues and barriers faced by their clusters.

Our synergistic approach paints a picture of the industry clusters and the linkages within and between these clusters. Using existing data, the quadrant method provides a sound foundation for the classification of industry clusters. The focus groups and interviews afford extra key knowledge on the interconnections with firms, institutions, and other supporting infrastructure. They also provide a means to create cluster maps that can inform policy making. The information gained from our synergistic 
approach is invaluable for developing a tool that could help a local economy better understand the strengths and weaknesses in their economy.

In addition, compared to the more mathematically and theoretically complex approaches, our synergic approach could be applied on a more cost effective basis in a smaller community or region. In our project, we organized five focus groups with the Chamber of Commerce, economic development agencies, industry representatives, as well as over 26 interviews with business owners and managers. The total time spent by three researchers on focus groups and interviews, including planning and managing the process as well as time in the field, were roughly 110-120 hours. The people we invited were also very willing to participate in focus groups and interviews without any monetary incentives. Indeed, the total costs for conducting this project was marginal. We believe this is an important advantage for smaller to medium-sized communities that have limited budgets.

Finally, in contrast to the more mathematically driven approaches that become a black box that few understand, the transparency of our approach creates an accessible methodology that gives a community a greater on the ground understanding of their local economy. When the local community takes the initiative to study their own economy they not only understand the outcomes of the analysis better, but also develop important business contacts as well as can complete a cost-effective analysis when compared to a more mathematical approach. Furthermore, the focus groups and interviews can lead to better community "buy-in" as business and individuals become an engaged part of the process of understanding and analyzing the economic cluster dynamics in their community.

\section{Conclusions}

The synergistic approach applied in this research holds the opportunity for virtually any size community to know more about its economic strengths and weaknesses and get a sense of where to target their energies to improve their industry sub-sectors in each of the four quadrants. In doing so, this research subscribes to the approach proposed by Peters (2005) when examining labor complexes in Missouri. 
Following Peters' approach makes it possible to learn more about labor and knowledge spillovers within a region's shared labor force.

In summary, the benefits of our synergic approach are multifold. Our quadrant analyses highlight a variety of employment opportunities that may be needed by different industries (complete results can be access at http://career.boisestate.edu/collegiate-employmentworkforce-readiness/). Yet, without coupling quantitative analyses of industry sector (or sub-sector) level employment data with specific employer needs through focus groups and interviews, it is difficult to understand the linkage within or between industries, as well as to predict the demand for specific fields or occupations and therefore the demand for shared labor force in the region. Our synergistic approach is a more prudent method to project future regional workforce needs through interviewing those companies from four quadrants (emerging, growing, declining, transforming) of industry sectors and sub-sectors on how they fit with the current workforce, what benefits the region is offering them, and what challenges the industries are facing.

The cluster maps derived from focus groups and interviews also help demonstrate the interconnectedness of industries and the sufficiency of regional resources including labor and infrastructure. The maps eloquently demonstrate the way a community's industries and resources are interrelated and foster the economy of the community. They may be of use to identify potential strengths for new industries to be developed and for businesses to innovate. More sophisticated methods such as social network analysis in addition to interviews and focus groups could be employed to help identify the direction and strength of the linkages and potential areas that may be ripe to foster new businesses or innovations. Perhaps most importantly, this methodology provides a battery of tools for communities of all sizes, especially those with limited resources and technical skills, as they prepare themselves in a global era of competition and transition. 


\section{References}

Austrian, Z. (2000). Cluster case studies: The marriage of quantitative and qualitative information for action. Economic Development Quarterly, 14(1), 97-110.

Blakely, E. J. \& Green- Leigh L. (2010). Planning local economic development: Theory and practice. Thousand Oaks, CA: Sage Publications.

Boschma, R., \& Kloosterman, R. (2005). Clustering, learning and regional development. In R. Boschma \& R. Kloosterman (Eds). Learning from cluster. A critical assessment from an economic geographical perspective (pp.1-18). Dordecht, Netherlands: Springer.

Held, J. R. (2004). Regional variation and economic drivers: An application of the Hill and Brennan methodology. Economic Development Quarterly, 18(4), 384-405.

Hill, E. W., \& Brennan, J.F. (2000). A methodology for identifying the drivers of industrial clusters: The foundation of regional competitive advantage. Economic Development Quarterly, 14(1), 65-96

Koo, J. (2005). Knowledge-based industry clusters: Evidenced by geographical patterns of patents in manufacturing. Urban Studies, 42(9), 1487-1505.

Martin, R., \& Sunley, P. (2003). Deconstructions clusters: Chaotic concept or policy panacea? Journal of Economic Geography, 3(1), 5-35.

Public Broadcast System (2013, January)). School of wine: Training students for jobs in Washington. The nightly news hour. [Tevevison broadcast]. Retrieved, January 8, 2013, from www.pbs.org/ newshour/bb/education/jan-june13/wine_01-01.html.

Parr, J. B. (2002). Missing Elements in the analysis of agglomeration economies. International Regional Science Review, 25(2), 151-168.

Peters, D. J. (2005).Using labor-based industry complexes for workforce development in Missouri. Economic Development Quarterly, 19(2), 138-156.

Porter, M.E. (1998). Clusters and the new economics of competition. Harvard Business Review. 
November-December.

Reid, N., Smith B. W., \& Carroll, M.C. (2008). Cluster regions: A social network approach. Economic Development Quarterly, 22(4), 345-352. 


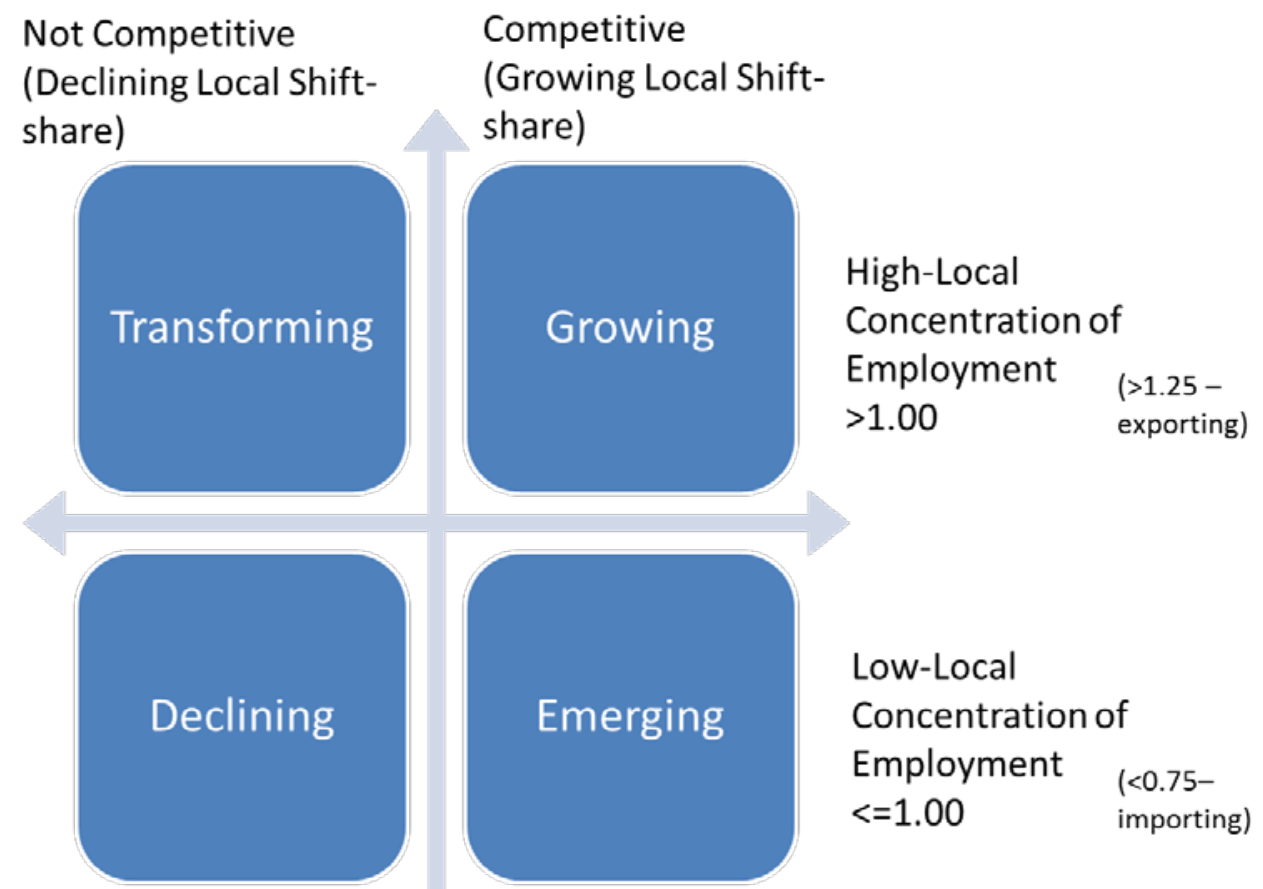

Figure 1. Quadrant Method 


\begin{tabular}{|c|c|c|c|c|c|c|}
\hline Final Markets & $\begin{array}{l}\text { Retail-grocery } \\
\text { outlets }\end{array}$ & $\begin{array}{l}\text { Food Service - } \\
\text { restaurants } \\
\text { both fast } \\
\text { food to high- } \\
\text { end } \\
\text { restaurants }\end{array}$ & $\begin{array}{l}\text { Institutional - } \\
\text { schools, } \\
\text { airlines, cruise } \\
\text { ships, hospitals }\end{array}$ & $\begin{array}{l}\text { Industrial - } \\
\text { sells product } \\
\text { to go into } \\
\text { further } \\
\text { processing - } \\
\text { e.g. potatoes } \\
\text { into canned } \\
\text { soup or } \\
\text { casserole }\end{array}$ & & \\
\hline $\begin{array}{l}\text { Distribution } \\
\text { Channels }\end{array}$ & $\begin{array}{l}\text { Food } \\
\text { Distribution } \\
\text { Center - not } \\
\text { company owned } \\
\text { - trucking/rail }\end{array}$ & $\begin{array}{l}\text { Food } \\
\text { Distribution } \\
\text { Center - } \\
\text { company } \\
\text { owned - } \\
\text { trucking/rail }\end{array}$ & $\begin{array}{l}\text { Internal } \\
\text { business } \\
\text { distribution } \\
\text { directly to } \\
\text { customer - } \\
\text { trucking }\end{array}$ & $\begin{array}{l}\text { Contract } \\
\text { trucking from } \\
\text { factory to } \\
\text { distribution } \\
\text { center }\end{array}$ & $\begin{array}{l}\text { Business } \\
\text { owned } \\
\text { trucks from } \\
\text { factory to } \\
\text { distribution } \\
\text { center }\end{array}$ & \\
\hline $\begin{array}{l}\text { Export } \\
\text { Products }\end{array}$ & $\begin{array}{l}\text { Cultured } \\
\text { products - sour } \\
\text { cream and } \\
\text { cottage cheese }\end{array}$ & Fluid milk & Powdered milk & Butter & $\begin{array}{l}\text { Italian } \\
\text { Cheese }\end{array}$ & $\begin{array}{l}\text { Whey } \\
\text { products }\end{array}$ \\
\hline Suppliers & $\begin{array}{l}\text { Raw milk - } \\
\text { mostly from } \\
\text { [State removed } \\
\text { for review } \\
\text { purposes]and } \\
\text { some from } \\
\text { neighboring } \\
\text { states, but } \\
\text { pretty much } \\
\text { from [State } \\
\text { removed for } \\
\text { review } \\
\text { purposes] }\end{array}$ & $\begin{array}{l}\text { Different } \\
\text { cultures to } \\
\text { make cheese } \\
\text { or butter; not } \\
\text { in [State } \\
\text { removed for } \\
\text { review } \\
\text { purposes] }\end{array}$ & $\begin{array}{l}\text { Packaging } \\
\text { materials }\end{array}$ & & & \\
\hline $\begin{array}{l}\text { Specialized } \\
\text { Community } \\
\text { Infrastructure }\end{array}$ & $\begin{array}{l}\text { Irrigation } \\
\text { Network; [Name } \\
\text { Removed for } \\
\text { Review] River }\end{array}$ & $\begin{array}{l}\text { State grants } \\
\text { for employee } \\
\text { training }\end{array}$ & Power & Road network & water & $\begin{array}{l}\text { Waste } \\
\text { handling }\end{array}$ \\
\hline Threats & $\begin{array}{l}\text { Sewage } \\
\text { Treatment and } \\
\text { road } \\
\text { infrastructure }\end{array}$ & $\begin{array}{l}\text { Urban/Rural } \\
\text { Conflict - } \\
\text { noise, odor, } \\
\text { population } \\
\text { expansion } \\
\text { pushing ag } \\
\text { further into } \\
\text { periphery }\end{array}$ & $\begin{array}{l}\text { Workforce } \\
\text { development; } \\
\text { Higher-end } \\
\text { labor - } \\
\text { engineers, } \\
\text { management }\end{array}$ & $\begin{array}{l}\text { Focus on high- } \\
\text { tech and other } \\
\text { industries from } \\
\text { government - } \\
\text { neglect of } \\
\text { agriculture - } \\
\text { leads to a lack of } \\
\text { infrastructure } \\
\text { projects and } \\
\text { funding to } \\
\text { bolster ag }\end{array}$ & & \\
\hline
\end{tabular}

Figure 2. Cluster Map of Dairy Processing in Boise-Nampa MSA 


\begin{tabular}{|c|c|c|c|c|c|c|}
\hline Final Markets & $\begin{array}{l}\text { Retail - } \\
\text { grocery } \\
\text { outlets }\end{array}$ & $\begin{array}{l}\text { Food Service - } \\
\text { restaurants } \\
\text { both fast food } \\
\text { and high-end } \\
\text { restaurants }\end{array}$ & $\begin{array}{l}\text { Institutional - } \\
\text { schools, } \\
\text { airlines, cruise } \\
\text { ships, } \\
\text { hospitals }\end{array}$ & $\begin{array}{l}\text { Industrial - } \\
\text { sells product } \\
\text { to go into } \\
\text { further } \\
\text { processing - } \\
\text { potatoes into } \\
\text { canned soup }\end{array}$ & $\begin{array}{l}\text { Animal feed } \\
\text { for } \\
\text { cattle/livestock }\end{array}$ & \\
\hline $\begin{array}{l}\text { Distribution } \\
\text { Channels }\end{array}$ & $\begin{array}{l}\text { Food } \\
\text { Distribution } \\
\text { Center - not } \\
\text { company } \\
\text { owned - } \\
\text { trucking/rail }\end{array}$ & $\begin{array}{l}\text { Food } \\
\text { Distribution } \\
\text { Center - } \\
\text { company } \\
\text { owned - } \\
\text { trucking/rail }\end{array}$ & $\begin{array}{l}\text { Internal } \\
\text { business } \\
\text { distribution } \\
\text { directly to } \\
\text { customer - } \\
\text { trucking }\end{array}$ & $\begin{array}{l}\text { Contract } \\
\text { trucking from } \\
\text { factory to } \\
\text { distribution } \\
\text { center }\end{array}$ & $\begin{array}{l}\text { Business } \\
\text { owned trucks } \\
\text { from factory to } \\
\text { distribution } \\
\text { center }\end{array}$ & \\
\hline $\begin{array}{l}\text { Export } \\
\text { Products }\end{array}$ & $\begin{array}{l}\text { French fries - } \\
\text { shoestring, } \\
\text { lattice cuts, } \\
\text { curly, etc. }\end{array}$ & $\begin{array}{l}\text { Breakfast } \\
\text { hash browns }\end{array}$ & $\begin{array}{l}\text { IQF - } \\
\text { Individually } \\
\text { Quick Frozen } \\
\text { products - } \\
\text { Cubed or } \\
\text { sliced } \\
\text { potatoes }\end{array}$ & & & \\
\hline Suppliers & $\begin{array}{l}\text { Raw } \\
\text { Commodity } \\
\text { from [State } \\
\text { removed for } \\
\text { review } \\
\text { purposes], } \\
\text { \{removed for } \\
\text { review, and } \\
\text { removed for } \\
\text { review] - } \\
\text { proximity is } \\
\text { important }\end{array}$ & $\begin{array}{l}\text { Cooking Oil } \\
\text { from outside } \\
\text { [State } \\
\text { removed for } \\
\text { review } \\
\text { purposes] }\end{array}$ & $\begin{array}{l}\text { Non-food } \\
\text { contact } \\
\text { packaging } \\
\text { materials - } \\
\text { cardboard } \\
\text { boxes to ship } \\
\text { bulk supply of } \\
\text { product - } \\
\text { Some from } \\
\text { [State } \\
\text { removed for } \\
\text { review } \\
\text { purposes] }\end{array}$ & $\begin{array}{l}\text { Food contact } \\
\text { packaging } \\
\text { materials - } \\
\text { plastic } \\
\text { sheathing } \\
\text { around frozen } \\
\text { French fries - } \\
\text { Not in [State } \\
\text { removed for } \\
\text { review } \\
\text { purposes] }\end{array}$ & $\begin{array}{l}\text { Food } \\
\text { processing } \\
\text { equipment; in } \\
\text { [Area removed } \\
\text { for review } \\
\text { purposes]and } \\
\text { [State } \\
\text { removed for } \\
\text { review } \\
\text { purposes] }\end{array}$ & \\
\hline $\begin{array}{l}\text { Specialized } \\
\text { Community } \\
\text { Infrastructure }\end{array}$ & $\begin{array}{l}\text { Irrigation } \\
\text { Network; } \\
\text { [Removed for } \\
\text { review] River }\end{array}$ & $\begin{array}{l}\text { State grants } \\
\text { for employee } \\
\text { training }\end{array}$ & Power & Road network & water & $\begin{array}{l}\text { Waste } \\
\text { handling }\end{array}$ \\
\hline Threats & $\begin{array}{l}\text { Sewage } \\
\text { Treatment } \\
\text { and road } \\
\text { infrastructure }\end{array}$ & $\begin{array}{l}\text { Urban/Rural } \\
\text { Conflict - } \\
\text { noise, odor, } \\
\text { population } \\
\text { expansion } \\
\text { pushing ag } \\
\text { further into } \\
\text { periphery }\end{array}$ & $\begin{array}{l}\text { Workforce } \\
\text { development; } \\
\text { Higher-end } \\
\text { labor - } \\
\text { engineers, } \\
\text { management }\end{array}$ & $\begin{array}{l}\text { Focus on high- } \\
\text { tech and other } \\
\text { industries from } \\
\text { government - } \\
\text { neglect of } \\
\text { agriculture - } \\
\text { leads to a lack } \\
\text { of } \\
\text { infrastructure } \\
\text { projects and } \\
\text { funding to } \\
\text { bolster ag }\end{array}$ & $\begin{array}{l}\text { Health related } \\
\text { concerns }\end{array}$ & \\
\hline
\end{tabular}

Figure 3. Cluster Map of Frozen Potato Processing in Boise-Nampa MSA 
Table 1. Questions for Focus Groups

Questions
In your opinion, what makes the [name removed for review] area competitive for the growing and emerging
industries listed in the quadrants? (i.e., what are the regions strengths?)
In your opinion, what makes the [name removed for review] area attractive to expand or locate business
operations? (i.e., what are the regions opportunities?)
In general, are there industries not represented in the region that could be? Why might they not be here
yet?
How does knowledge transfer occur in the workplace? Across businesses? Across industries?
Is there anything we have not asked you about the regional economy that you think would be important for
us know as we work to align workforce needs and education in the region?


Table 2. Interview Questions

\begin{abstract}
Questions
1) Company Background: What are the company's product lines? What is the company's specialty in the [name removed for review] MSA? Where are the non-[name removed for review] MSA facilities located?

2) Location decision: How long has the company been located in the [name removed for review] MSA? Why is it located in here? Is the company planning to expand locally? Are there any barriers to expansion? What competitive advantages does the [name removed for review] region offer?

3) Cluster Relationships: Who are the customer industries, and where are they located? Has the customer base changed over time? Is being near customers important? Who are the supplier industries, and where are they located? Has the supplier base changed over time? Is being near suppliers important?
\end{abstract}

4) Cluster networking and possibilities for collaborative action: Does the company interact with other firms in the industry? Does the company belong to trade associations or other organizations? Does the company have relationships with local universities? Is the company interested in collaboration? What can be done to encourage more collaboration? On what can companies in the industry collaborate?

5) Requirement's for cluster growth: Several questions were asked on workforce issues. What are the major occupations categories in the company? Which ones are growing? What skills are important? Are important skills missing in the [name removed for review] region? What other regional assets could be required for growth such as research based, transportation infrastructure, telecommunications, access to capital, regulatory climate and amenities?

6) Opportunities for growth: What is the future for the industry in the [name removed for review] region? What are the effects of global changes? What is the impact of technology?

7) Is there anything we did not ask you about that you think would be important for our research?

8) Is there anyone else that you recommend I should speak with in your industry? 
Table 3. Food Processing Cluster Mapping Questions

\section{Questions}

1) What are the larger or more significant food processing industries in the [name removed for review] MSA? Have some been here longer than others? Why? Why did they locate here?

2) Location decision/industry background: How long has food processing been located in the [name removed for review] MSA? Why is it located here? Are there any known food processing -related expansions occurring locally? In general or for particular product lines are there any barriers to expansion? What competitive advantages does the [name removed for review] region offer the food processing industry or specific product lines?

3) Industry Relationships: Who are the typical customer-industries of the products generated by the food processing industries and where are they located? Has the customer base changed over time? Is being near customers important? Who are the supplier industries and where are they located? Has the supplier base changed over time? Is being near suppliers important?

4) Industry Distribution: How are the products distributed within the [name removed for review] MSA and outside the region? Is the distribution of products handled by the firms in question or are they outsourced to another firm specializing in distribution? Are there any recent trends in the distribution process? Are there alternatives to these methods? If not, why not?

5) Industry Exports: What are the major products exported outside the [name removed for review] MSA by the food processing industries? Where are the major products being exported going? What are products exported utilized for, such as further processing or consumption?

6) Industry networking and possibilities for collaborative action: Does the food processing Industry interact with other food or processing industries in the area? Is there a trade association or other organization for food processing businesses to belong or interact with? Does the food processing industry maintain relationships with local universities? Is the industry interested in collaboration? What can be done to encourage more collaboration within the food processing industry itself and between the businesses with other industries or other area institutions? On what can the food processing industry collaborate?

7) Requirement's for industry growth: Several questions were asked on workforce issues. What are the major industry categories in the food processing cluster? Which ones are growing? What skills are important for the industry as a whole? Are important skills missing in the [name removed for review] region for the industry in general or specific areas? What community infrastructure is essential to the food processing industry, such as research based, transportation infrastructure, telecommunications, access to capital, regulatory climate and amenities? What other community infrastructure could be required for growth?

8) Opportunities for growth: What is the future for the food processing industry in the [name removed for review] region? What are the effects of global changes? What is the impact of technology?

9) Is there anything we did not ask you about that you think would be important for our research? 
Table 4: Industry Sectors Drawn from for Interviews by Quadrant

\begin{tabular}{|c|c|}
\hline Transforming & Growing \\
\hline $\begin{array}{l}\text { - } \quad \text { Computer and Electronic Manufacturing } \\
\text { - Heavy and Civil Engineering Construction } \\
\text { - } \quad \text { Food Product Manufacturing } \\
\text { - Furniture and Home Furnishings } \\
\end{array}$ & $\begin{array}{l}\text { - Administrative and Support Services } \\
\text { - Agriculture and Food Processing } \\
\text { - Sporting Goods, Hobby, Book and Music Stores }\end{array}$ \\
\hline Declining & Emerging \\
\hline $\begin{array}{l}\text { - Transportation Equipment Manufacturing } \\
\text { - } \quad \text { Furniture and Related Product Manufacturing } \\
\text { - Machinery Manufacturing }\end{array}$ & $\begin{array}{l}\text { - Personal and Laundry Services } \\
\text { - Utilities } \\
\text { - Performing Arts, Spector Sports, and Related } \\
\text { - Industries } \\
\text { - Professional, Scientific and Technical Services }\end{array}$ \\
\hline
\end{tabular}




\footnotetext{
${ }^{1}$ In very small communities, publicly accessible employment data may be incomplete or only exist at an aggregated level due to non-disclosure agreements between businesses and the government agencies that collect this information. However, in these communities, we typically have a pretty good sense of what industries are growing or emerging and what industries are transforming or declining. As such, the identification of businesses in specific industries for interviews and focuses groups could be easily achieved without conducting the quadrant analysis as we proposed

${ }^{2}$ Italics in the original

${ }^{3}$ Idaho is not unique in the provision of a business directory through its labor department. However, if a business directory is not available through the local labor department, other sources do exist. In some counties, Idaho County for example, the local library maintains a subscription to Reference USA, which includes businesses by industry.
} 